\title{
A Neural Network Model for Ultrasonic Pulse Velocity and the Modulus of Elasticity of Polymer Concrete
}

\author{
Barış Şimşek ${ }^{1}$, and Tayfun Uygunoğlu ${ }^{2}$
}

\begin{abstract}
In this study, polymer concrete properties such as ultrasonic pulse velocity and the modulus of elasticity were modeled by artificial neural network. Seven polymers were selected as high density polyethylene, low density polyethylene, polypropylene, thermoplastic elastomer, dimethyl terephthalate, polyethylene terephthalate, polyethylene naphthalate and twenty-seven experiments was used to train the network. Two type of network training such as cascade forward back prop and feed forward back prop containing one hidden layer which has ten neurons was compared to predict the ultrasonic pulse velocity and the modulus of elasticity. Moreover, five experiments were used for comparing of the network models. The result show that feed forward back prop type training is more effective to predict the ultrasonic pulse velocity and the modulus of elasticity of polymer concrete comparing the cascade forward back prop training type.
\end{abstract}

Keywords-A Neural Network Model, Polymer Concrete, Ultrasonic Pulse Velocity and the Modulus of Elasticity.

\section{INTRODUCTION}

$\mathrm{I}_{\mathrm{s}}^{\mathrm{N}}$ $\mathrm{N}$ recent years, computational methods such as neural network (NN) are widely used to predict concrete properties. Some of these studies on various concrete types are as follows. Yan et al. [1] presumed the fracture parameters of the size effect model for concrete, Chen et al. [2] predicted the concrete properties, Wang et al. [3] estimated the expansion behavior of self-stressing concrete, Imam et al. [4] modeled residual strength of corroded reinforced concrete Beams. Kostic and Vasovic [5] built a model for compressive strength of basic concrete. Chithiraet al. [6] predicted the compressive strength of high strength concrete containing nano-silica, Yadollahi et al. [7] modeled the optimal mixture ratio of radiation shielding concrete, Jiang et al. [8] estimated the concrete corrosion, Şimşek et al. [9] predicted the normal weight concrete properties with fuzzy approach, Yan and Lin [10] evaluated the anchorage reliability of concrete. However, many of studies containing NN application do not involve any studies about evaluation of training parameters.

In this study, seven polymers were selected as high density polyethylene, low density polyethylene, polypropylene, thermoplastic elastomer, dimethyl terephthalate, polyethylene

\footnotetext{
${ }^{1}$ Department of Chemical Engineering, Faculty of Engineering, Çankırı Karatekin University, Çankırı, Turkey

${ }^{2}$ Depertment of Civil Engineering, Faculty of Engineering, Afyon Kocatepe University, Afyon, Turkey
}

terephthalate, polyethylene naphthalate and twenty-seven experiments was used to train the network. It was aimed to evaluate two type of network training such as cascade forward back prop and feed forward back prop containing one hidden layer which has ten neurons to predict concrete properties. The ultrasonic pulse velocity and the modulus of elasticity were determined as polymer concrete properties. Five experiments were used for comparing of the network models. In this purpose, two neural network models based on cascade forward back prop and feed forward back prop training algorithm was built via Matlab ${ }^{\circledR}$ version 2011b. To evaluate two training algorithm for prediction polymer concrete properties, regression coefficients obtained by five experiments were used.

\section{MATERIALS AND METHODOLOGY}

\section{A. Materials}

High density polyethylene, low density polyethylene, polypropylene and polyethylene terephthalate was supplied from plastic recycling plant; the other was also procured from plastic granule manufacturers. All polymers' granule size is smaller than $4 \mathrm{~mm}$. They are used to instead of fine aggregate. The density of used polymers in this study varies 0.90 between $1.38 \mathrm{~kg} / \mathrm{m}^{3}$. Thirteen inputs including cement, water, fly ash, and super plasticizer, fine and coarse aggregate and two outputs such as ultrasonic pulse velocity and the modulus of elasticity were used to build the neural network.

\section{B. Proposed Methodology}

Proposed methodology has five steps was given as follows. The neural network model was built via Matlab ${ }^{\circledR}$ version 2011b. The regression coefficients obtained by five experiments were used to predict polymer concrete. 


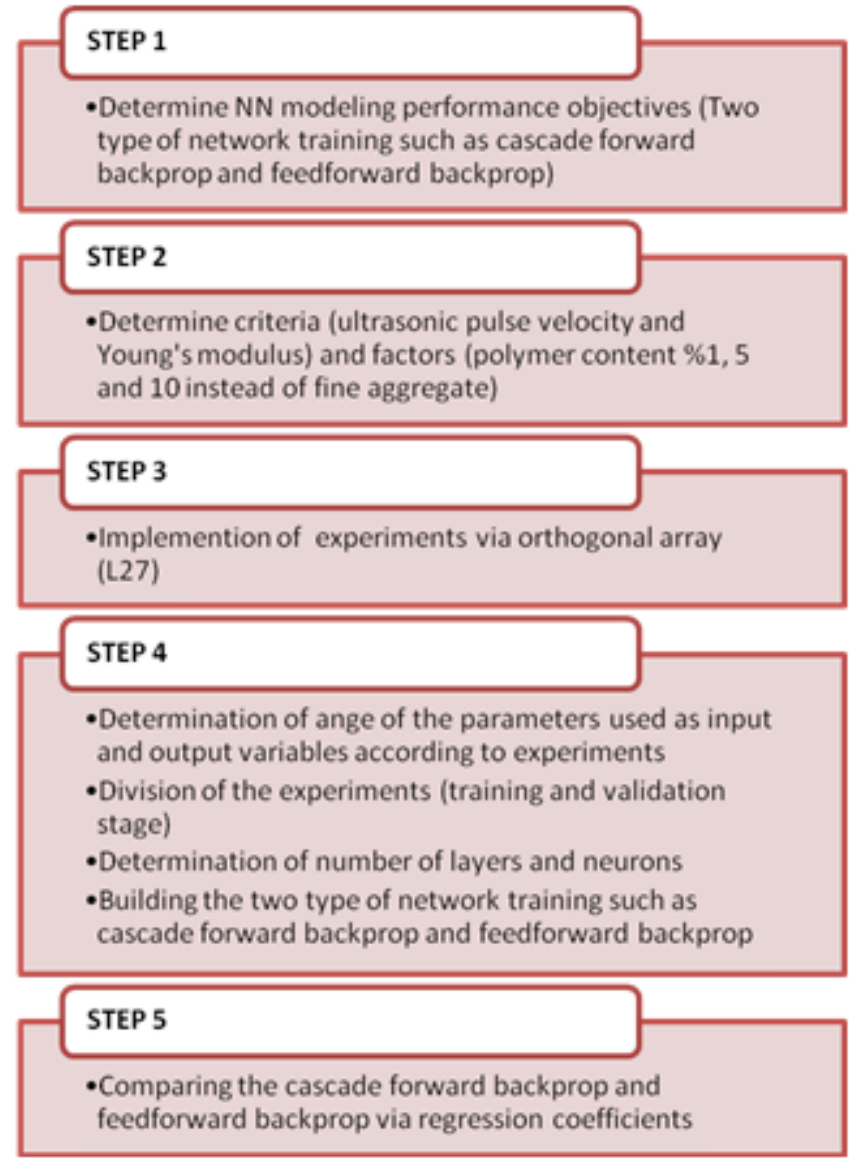

Fig. 1: Proposed methodology

\section{Input and Output Variables}

The range of the parameters used as input and output variables are presented in Table 1 and Table 2, respectively.

TABLE I: THE RANGE OF THE PARAMETERS USED AS INPUT VARIABLES $\left(30 \mathrm{DM}^{3}\right)$

\begin{tabular}{|c|c|c|c|}
\hline \multirow[t]{2}{*}{ INPUTS } & \multirow[t]{2}{*}{ DESCRIPTION } & \multicolumn{2}{|c|}{$\begin{array}{l}\text { DATA USED IN ANN } \\
\text { MODEL } \\
\end{array}$} \\
\hline & & MINIMUM & MAXIMUM \\
\hline $\mathrm{X}_{1}$ & HIGH DENSITY POLYETHYLENE (\%) & 70 & 1170 \\
\hline $\mathrm{X}_{2}$ & LOW DENSITY POLYETHYLENE (\%) & 70 & 1170 \\
\hline $\mathrm{X}_{3}$ & POLYPROPYLENE (\%) & 70 & 1170 \\
\hline $\mathrm{X}_{4}$ & THERMOPLASTIC ELASTOMER (\%) & 70 & 1170 \\
\hline $\mathrm{X}_{5}$ & DIMETHYL TEREPHTHALATE (\%) & 70 & 1170 \\
\hline $\mathrm{X}_{6}$ & POLYETHYLENE TEREPHTHALATE (\%) & 70 & 1170 \\
\hline $\mathrm{X}_{7}$ & POLYETHYLENE NAPHTHALATE (\%) & 70 & 1170 \\
\hline $\mathrm{X}_{8}$ & CEMENT DOSAGE (KG) & 10.5 & 13.5 \\
\hline $\mathrm{X}_{9}$ & FLY ASH CONTENT (KG) & 2.6 & 3.4 \\
\hline $\mathrm{X}_{10}$ & WATER TO BINDER RATIO & 4.2 & 6.8 \\
\hline $\mathrm{X}_{11}$ & SUPER PLASTICIZER CONTENT (\%) & 0.09 & 0.2 \\
\hline $\mathrm{X}_{12}$ & $\begin{array}{lccc}\text { FINE } & \text { AGGREGATE } & \text { TO } & \text { TOTAL } \\
\text { AGGREGATE RATIO } & & \\
\end{array}$ & 7.8 & 25 \\
\hline $\mathrm{X}_{13}$ & $\begin{array}{l}\text { COARSE AGGREGATE (I) TO TOTAL } \\
\text { AGGREGATE RATIO }\end{array}$ & 18 & 32 \\
\hline
\end{tabular}

TABLE II: THE RANGE OF THE PARAMETERS USED AS OUTPUT VARIABLES

\begin{tabular}{|c|c|c|c|c|}
\hline QUALITY & SYMBOL & DESCRIPTION & DATA USED & NN MODEL \\
\hline CHARACTERISTIC & & & MINIMUM & MAXIMUM \\
\hline 1 & R1 & $\begin{array}{c}\text { ULTRASONIC } \\
\text { PULSE } \\
\text { VELOCITY } \\
(\mathrm{KM} / \mathrm{H})\end{array}$ & 2.95 & 4.87 \\
\hline 2 & R2 & $\begin{array}{c}\text { THE } \\
\text { MODULUS OF } \\
\text { ELASTICITY } \\
\text { (MPA) }\end{array}$ & 19000 & 53000 \\
\hline
\end{tabular}

\section{Building the Neural Network Model}

In this part of study, a NN model was presented to predict the effect of factors on the polymer concrete properties such as ultrasonic pulse velocity and the modulus of elasticity.

Multilayer cascade forward back prop (Figure 2) and feed forward network back prop (Figure 3) model and have been trained with Levenberg-Marquardt (LM) training algorithm [11].

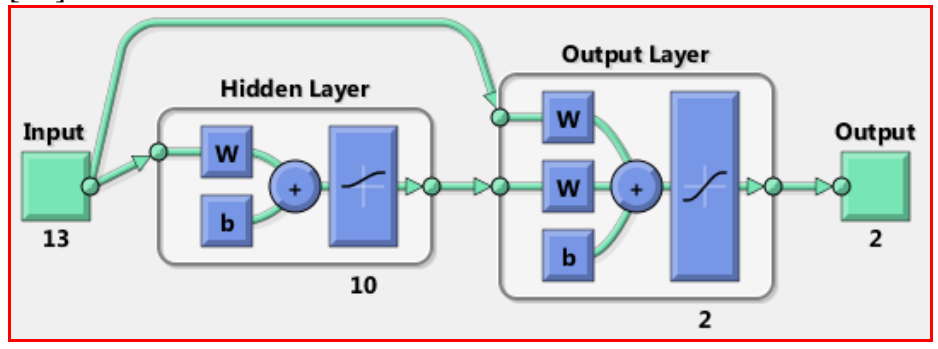

Fig. 2: The ANN model used in this study obtained by Matlab (cascade forward back prop)

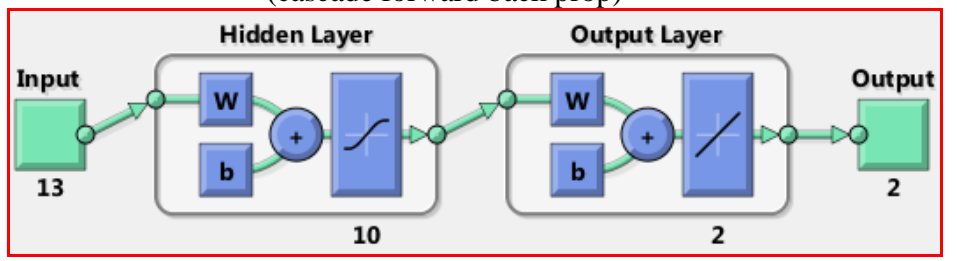

Fig. 3: The ANN model used in this study obtained by Matlab (feed forward back prop)

\section{RESULTS AND DISCUSSION}

The most appropriate results have been obtained from chosen network model in which tangent sigmoid and pure linear functions used as activation function for the hidden and output layer neurons, respectively. The values of parameters used in the chosen network models can be summarized as follows; the cascade forward back prop and feed forward network, adopted in this research, has 13 neurons (variables) in the input layer and 2 neurons in the output layer. One number of hidden layers; number of hidden layer neurons = 10; performance goal $=0$; and learning cycles $=300$ (Figure 2 and 3). Five experiments were carried out to predict ultrasonic pulse velocity and the modulus of elasticity of polymer concrete. Acquired regression coefficients for cascade forward and feed forward network were given in Figure 4 and 5, respectively. 


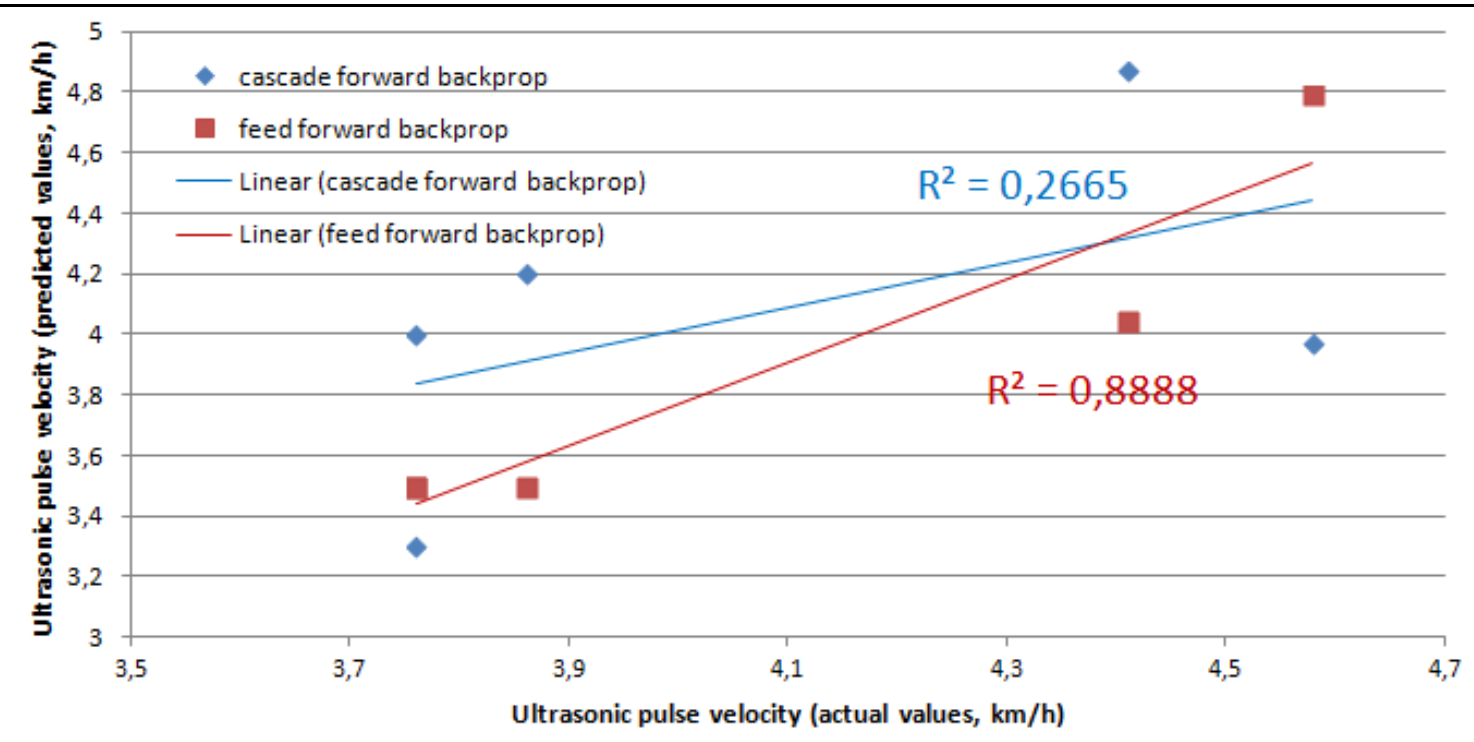

Fig. 4: The regression coefficients for ultrasonic pulse velocity

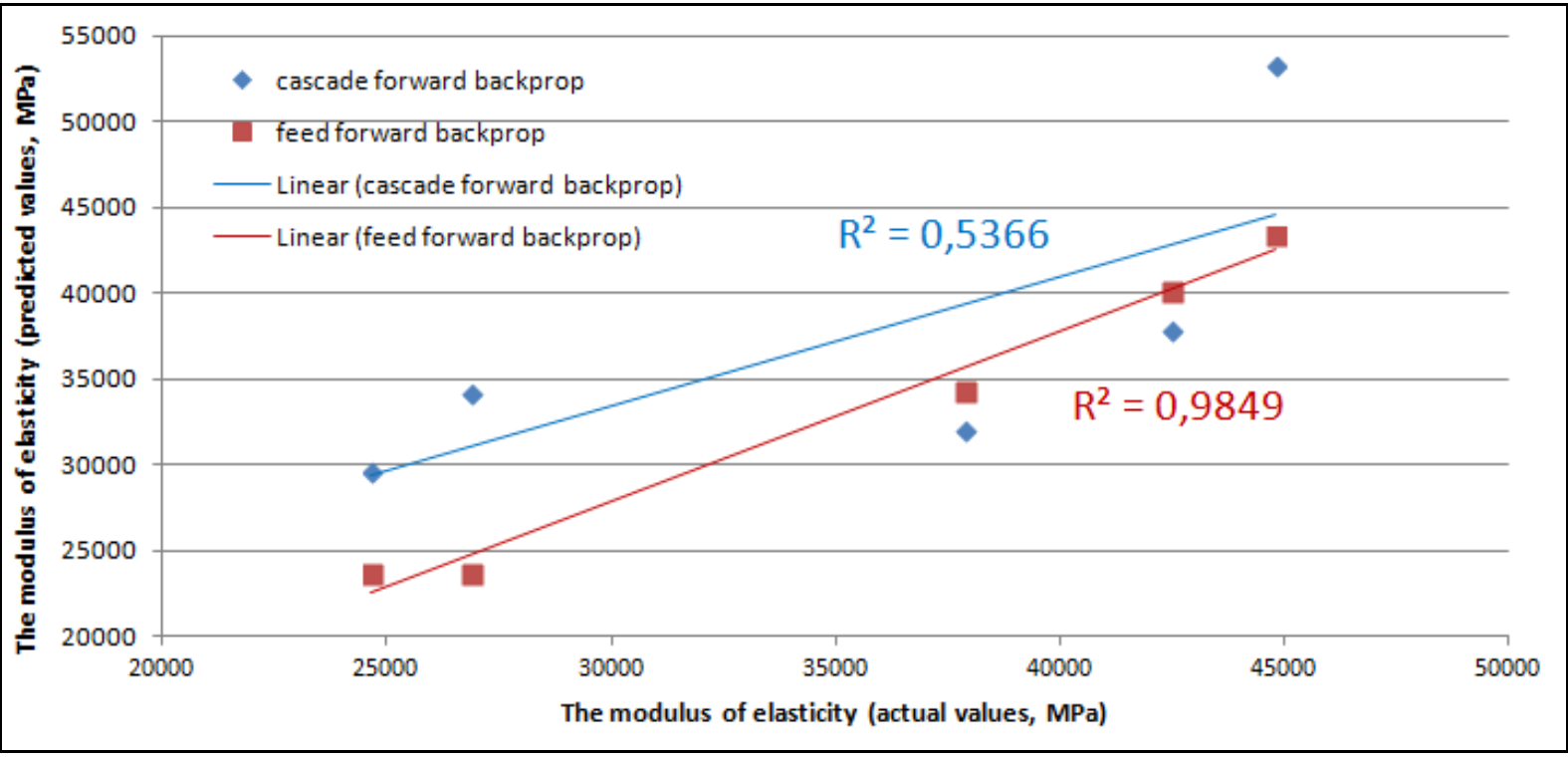

Fig. 5: The regression coefficients for the modulus of elasticity

\section{CONCLUDING REMARKS}

In this study, polymer concrete properties such as ultrasonic pulse velocity and the modulus of elasticity were modeled by artificial neural network. Two type of network training such as cascade forward back prop and feed forward back prop containing one hidden layer which has ten neurons was compared to predict the ultrasonic pulse velocity and the modulus of elasticity. The result show that feed forward back prop type training with a 0.8888 regression coefficient is more effective to predict the ultrasonic pulse velocity of polymer concrete comparing the cascade forward back prop training type with a 0.2665 regression coefficient. In addition, feed forward back prop type training with a 0.9849 regression coefficient is more effective to predict the modulus of elasticity of polymer concrete comparing the cascade forward back prop training type with a 0.5366 regression coefficient. The remarkable results also show that the choosing of training parameters affects the modeling performance.

\section{ACKNOWLEDGMENT}

This work was elaborated with the support of the Research Project (TUBITAK-MAG-214M392) funded by Turkish Scientific and Technical Research Institute. Authors thank to TUBITAK.

\section{REFERENCES}

[1] Y. Yan, Q. Ren and N. Xia, ”Artificial neural network approach to predict the fracture parameters of the size effect model for concrete", Fatigue \& Fracture of Engineering Materials \& Structures, vol. 38, Issue 11, pp. 1347-1358, 2015. http://dx.doi.org/10.1111/ffe.12309

[2] B. Chen, Q. Mao and J. Gao," Concrete properties prediction based on database”, Computers and Concrete, vol. 16, Issue 3, 343-356, 2015. http://dx.doi.org/10.12989/cac.2015.16.3.343 
[3] B. Wang, T. Man and H. Jin, "Prediction of expansion behavior of selfstressing concrete by artificial neural networks and fuzzy inference systems”, Construction and Building Materials, vol. 84, 184-191, 2016. http://dx.doi.org/10.1016/j.conbuildmat.2015.03.059

[4] A. Imam, F. Anifowose and A.K. Azad,"Residual Strength of Corroded Reinforced Concrete Beams Using an Adaptive Model Based on ANN", International Journal of Concrete Structures and Materials, vol. 9, Issue, 2, 159-172, 2015.

http://dx.doi.org/10.1007/s40069-015-0097-4

[5] S. Kostic and D. Vasovic, "Prediction model for compressive strength of basic concrete mixture using artificial neural networks", Neural Computing \& Applications, vol. 26, 1005-1024, 2015. http://dx.doi.org/10.1007/s00521-014-1763-1

[6] S. Chithra, S.R.R. Senthil Kumar, K. Chinnaraju and F.A. Ashmita, “A comparative study on the compressive strength prediction models for High Performance Concrete containing nano silica and copper slag using regression analysis and Artificial Neural Networks”, Construction and Building Materials, vol.114, 528-535, 2016. http://dx.doi.org/10.1016/j.conbuildmat.2016.03.214

[7] A. Yadollahi, E., Nazemi, A. Zolfaghari and A. M. Ajorloo, "Application of artificial neural network for predicting the optimal mixture of radiation shielding concrete", Progress in Nuclear Energy, vol. 89, 69-77, 2016.

http://dx.doi.org/10.1016/j.pnucene.2016.02.010

[8] G. Jiang, J. Keller, P.L. Bond and Z. Yuan, "Predicting concrete corrosion of sewers using artificial neural network" Water Research, vol. 92, 52-60, 2016.

http://dx.doi.org/10.1016/j.watres.2016.01.029

[9] B. Şimşek, Y.T. İç and E.H. Şimşek, "Hybridizing a fuzzy multiresponse Taguchi optimization algorithm with artificial neural networks to solve standard ready-mixed concrete optimization problems", International Journal of Computational Intelligence Systems, vol. 9, Issue 3, 525-543, 2016.

http://dx.doi.org/10.1080/18756891.2016.1175816

[10] F. Yan and Z. Lin, "New strategy for anchorage reliability assessment of GFRP bars to concrete using hybrid artificial neural network with genetic algorithm”, Composites Part B., vol. 92, 420-433, 2016. http://dx.doi.org/10.1016/j.compositesb.2016.02.008

[11] Özcan F., Atiş CD., Karahan O., Uncuoğlu E. and Tanyıldızı H. "Comparison of artificial neural network and fuzzy logic models for prediction of long-term compressive strength of silica fume concrete", Advances in Engineering Software, vol. 40, 856-863, 2009. http://dx.doi.org/10.1016/j.advengsoft.2009.01.005 